\title{
Pengendalian Motor DC Menggunakan Arduino Uno Pada Rancang Bangun Electrostatic Precipitator
}

\author{
Mochamad Hanif Dwi Wicaksono ${ }^{1}$, Widi Aribowo ${ }^{2}$ \\ 1,2 Jurusan Teknik Elektro, Fakultas Teknik, Universitas Negeri Surabaya \\ Hanip.wijck@gmail.com \\ 2widiaribowo@unesa.ac.id
}

\begin{abstract}
Abstrak - Pada penelitian ini, penggerak hammer pada plat collecting elektrode menggunakan mikrocontroller ardiuino uno sebagai penggerak motor DC. Tujuan dari penelitian ini adalah untuk menghasilkan pengendalian motor DC menggunakan Arduino uno pada rancang bangun electrostatic precipitator untuk pengendapan debu limbah industri. Prinsip kerja dari alat ini ketika saklar rangkaian control di on kan EC Centrifugal Fan akan bekerja selama 40 detik, kecepatan EC Centrifugal Fan dapat diatur dengan cara memutar potensio meter yang ada pada ruang controller. setelah 40 detik EC Centrifugal Fan akan mati dan motor hammer akan bekerja selama 20 detik untuk merontokan debuh yang menempel pada plat CE.
\end{abstract}

Kata kunci; Ardiuno uno, Electrostatic Precipitator

\begin{abstract}
In this research, The hammer drive preceptor on the collecting electrode plate was used an ardiuinouno microcontroller as a DC motor drive. The purpose of this study is to produce a DC motor control using Arduino uno on the design of electrostatic precipitators for the deposition of industrial waste dust. the working principle of this tool when the control circuit switch is on the EC Centrifugal Fan will working for 40 seconds, the EC Centrifugal Fan speed can be adjusted by rotating the potentiometer in the controller room. after 40 seconds, the EC Centrifugal Fan will turning off and the hammer motor will work for 20 seconds to knock down the stick on the CE plate.
\end{abstract}

Keywords: Ardiunouno, Electrostatic Precipitator

\section{PENDAHULUAN}

PT. Semen Indonesia (Persero) Tbk merupakan perusahaan yang bergerak di bidang industri semen. Semen Indonesia memiliki 3 pabrik dengan kapasitas terpasang 8,5 juta ton semen per tahun yang berlokasi di Tuban, Jawa Timur.Sejak beroperasi pada 1994 lalu, Semen Indonesia menurut Agung, telah melakukan upaya untuk menekan polusi. Hal ini menjadi kewajiban pokok perusahaan, yang harus memenuhi baku mutu udara seperti yang disyaratkan pemerintah. Bahkan, untuk mengurangi pencemaran, perusahaan memasang alat canggih bernama eletrostatic precipitator (EP) yang mampu menangkap debu sampai $99 \%$. Selain itu, di setiap pabrik dipasang 2 alat EP, sedangkan untuk coal mill sudah dilengkapi dengan 4 bag house filter. Untuk cement mill terdapat 11 bag house filter, dan di daerah unit pengantongan terdapat ratusan bag house filter berukuran kecil (Riski P, 2016).

Menurut buku Operation and Maintenance Manual For Electrostatic Precipitators, Electrostatic Precipitators (ESP)adalah perangkat kontrol partikel yang menggunakan kekuatan listrik untuk bergerak partikel keluar dari aliran gas yang mengalir dan ke pelat kolektor. Partikel diberi suatu muatan listrik dengan memaksa mereka untuk melewati korona, wilayah di mana aliran gas mengalir. Medan listrik yang memaksa partikel bermuatan ke dinding berasal dari elektroda dipertahankan pada tegangan tinggi di tengah jalur aliran. Setelah partikel dikumpulkan di piring, mereka harus dikeluarkan dari piring tanpa masukkan kembali ke dalam aliran gas. Ini biasanya dilakukan dengan mengetuk mereka lepas dari pelat, memungkinkan lapisan partikel yang terkumpul untuk meluncur ke dalam gerbong yang darinya mereka dievakuasi (EPA, 1985).Alat elektrostatik precipitator, sebagai penggerak hammer untuk plat collecting elektrode menggunakan motor AC 3 fasa. Sedangkan untuk protoptipe elektrostatic preciitator penggerak hammer pada plat collecting elektrode menggunakan mikrocontroller ardiuino uno sebagai penggerak motor DC

Arduino adalah kit elektronika atau papan rangkaian elektronik open source yang didalamnya terdapat komponen utama, yaitu sebuah chip mikrokontroller dengan jenis AVR dari perusahaan ATMEL. Mikrokontroller ini terdiri dari chip atau IC (integrated circuit)yang bisa diprogram menggunakan computer.Sehingga berdasarkan penjelasan di atas dan hasil observasi diperlukan adanya pengembangan pengendalian motor DC menggunakan Arduino uno pada rancang bangun 
electrostatic precipitator untuk pengendapan debu limbah industri. Untuk meningkatkan kinerja dari alat ESP

\section{METODE}

Prosedur penelitian Pengendalian Motor DC Menggunakan Arduino Uno pada Prototype ESP untuk Pengendapan Debu Limbah Industri dapat dilihat pada diagram alur penelitian pada gambar 1 :

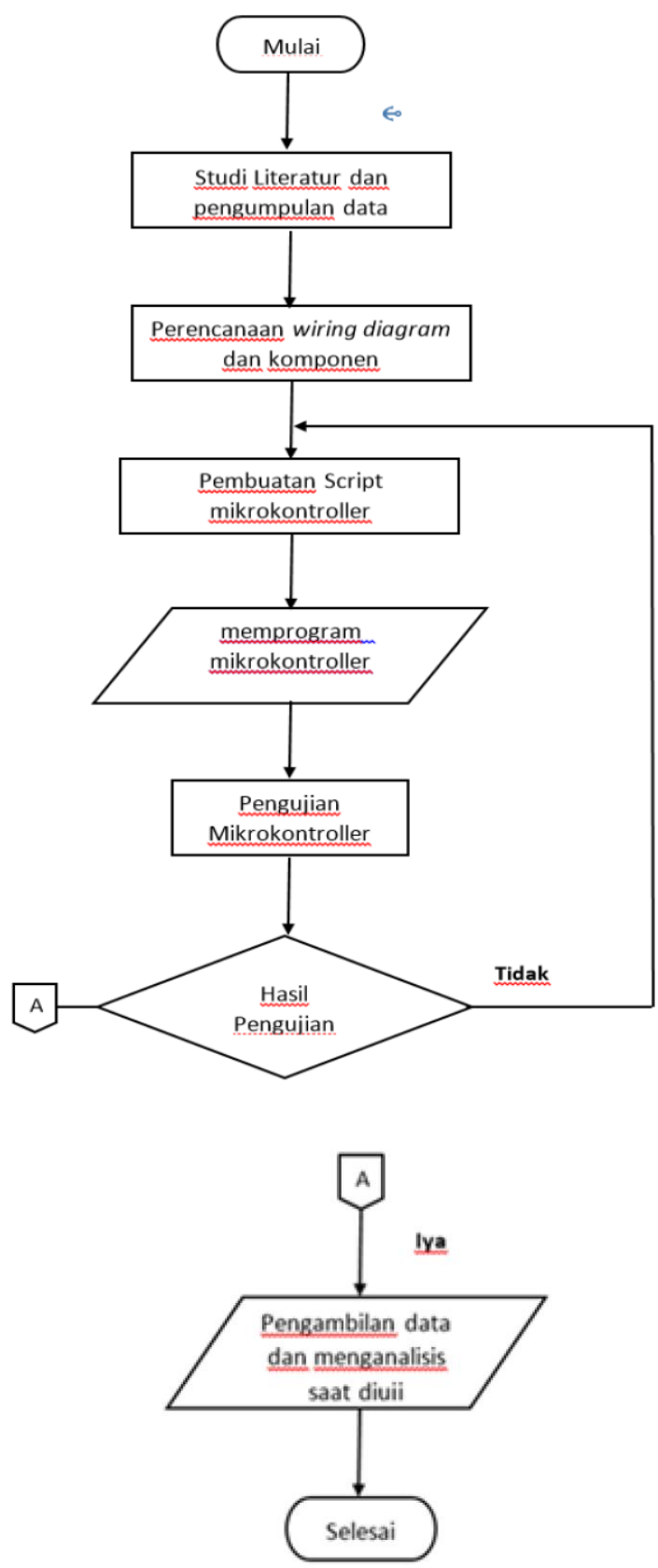

Gambar 1 Diagram alur penelitian

Pembuatan rangkaian skema mikrokontroler yang terdiri dariModul Relay, Motor DC Stepper $24 \mathrm{~V}$, kipas pc $24 \mathrm{~V}$ dan $12 \mathrm{~V}$, adaptor, Driver buck converter.kabel Male-female,
White Board. dengan menggunakan arduino uno tipe Arduino uno R3 sebagai otaknya.

Pemasangan mikrokontroler yang terdiridari script pemrograman yang sudah dibuat menggunakan Bahasa C pada softwere Arduino yang di transfer ke kit arduinouno R3, setelah itu rangkai semua komponen seusai dengan gambar 2 .

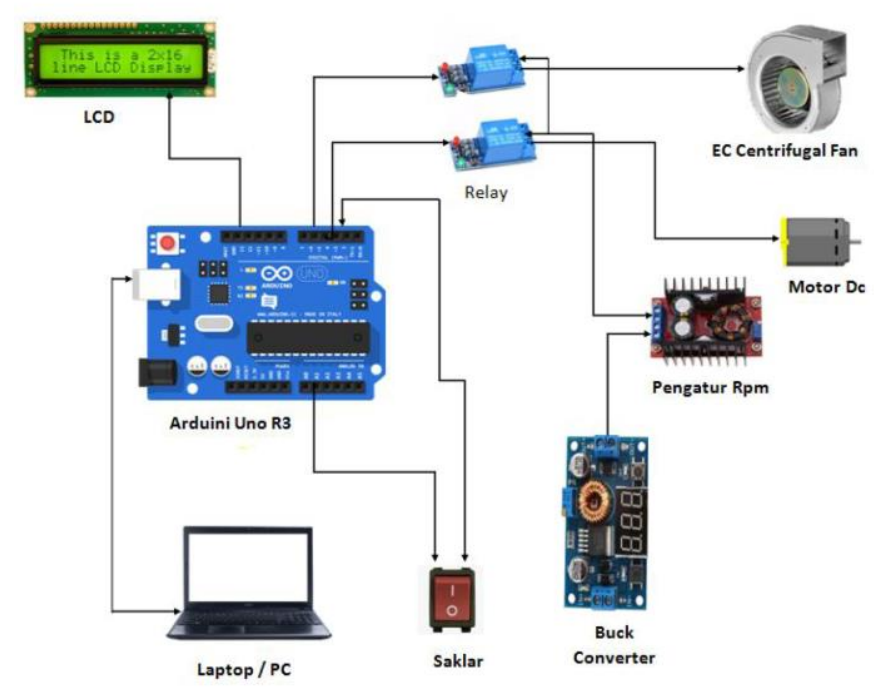

Gambar 2 wiring diagram mikrokontroller

Diagram Block Pengendalian Motor DC Diagram block pengendalian motor DC menggunakan Arduino uno pada rancang bangun electrostatic precipitator untuk pengendapan debu limbah industry dapat dilihat pada gambar

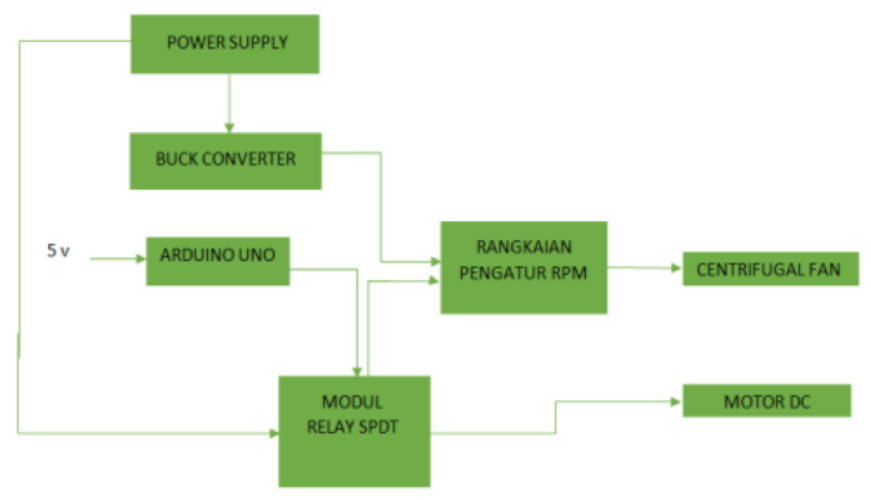

Gambar 3. wiring diagram mikrokontroller

Flowchart System Pengendalian Motor DC. 


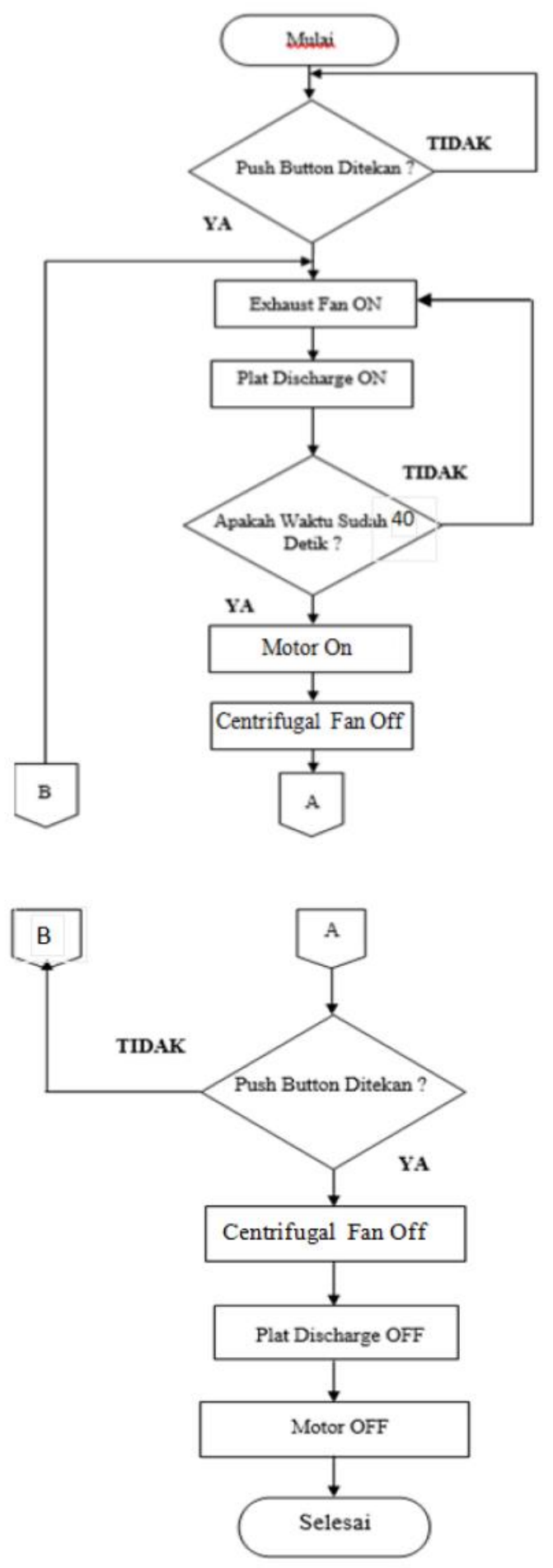

Gambar 4. wiring diagram mikrokontroller

DesainPenempatan Motor DC Terhadap Plat CE

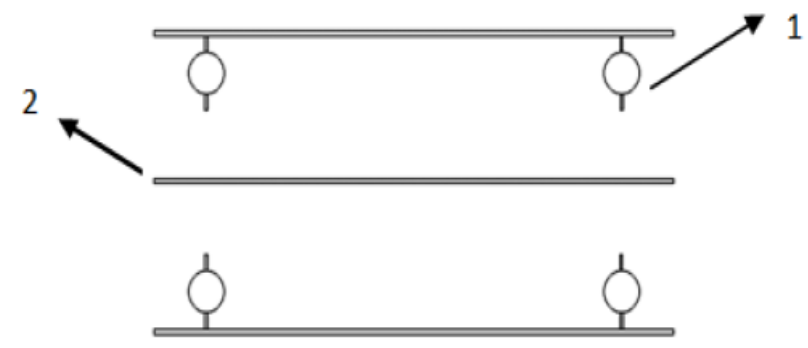

Gambar 5. Desain tampak atas penempatan motor DC

Keterangan desain :

1. Hosiden Motor De $24 \mathrm{~V}$

Hosiden Motor Dc $24 \mathrm{~V}$ berfungsi sebagai hammeruntuk menggetarkan Plat CE agar debu yang terkumpul pada Plat CE bisarontok ke bak penampung debu.

2. Plat Collecting Elektrode(CE)

Collecting Electrode berbentuk plat dengan bahan baku tembaga dengan jarak antar plat $10,5 \mathrm{~cm}$ hal tersebut bertujuan agar tingkat ektifitas antar plat dapat menangkap debu dengan bagus.

\section{Diagram Simulasi}

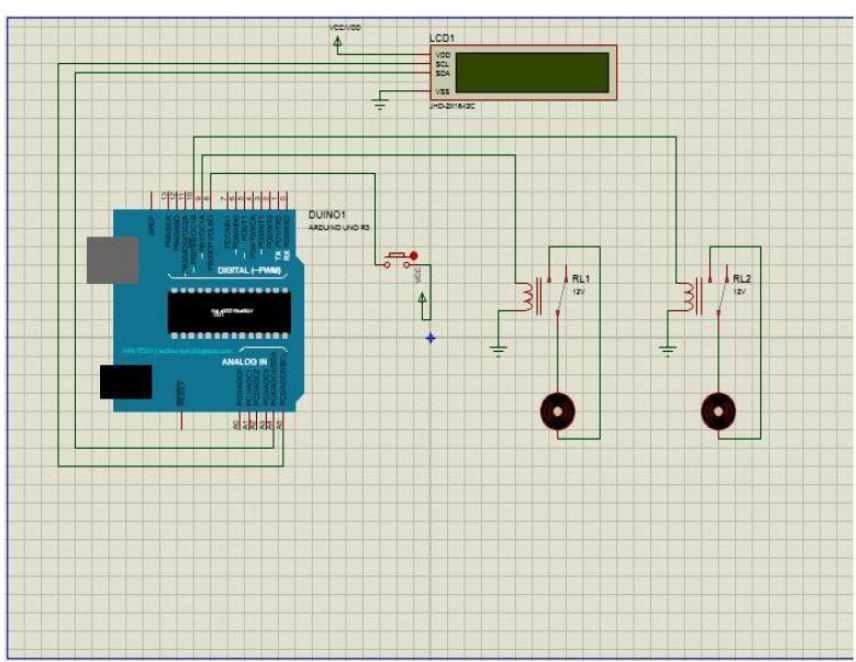

Gambar 6. SimulasiSoftwere Proteus

III. HASIL DAN PEMBAHASAN

\section{A. HASIL}

1. Kinerja Pengendalian Motor Dc menggunakan Arduino 
Uno Pengambilan data dari kinerja Pengendalian Motor Dc Menggunakan Arduino dengan menggunakan simulasi proteus, bawahsannya hasil dari simulasi apakah EBM Motor Centrifugaldan motor hammer bekerja sesuai dengan waktu yang telah ditentukan, berikut tabel 1 hasil analisis simulasi kinerja Pengendalian Motor Dc Menggunakan arduino dengan aplikasi proteus.

Tabel 1 hasil dari simulasi Pengendalian Motor Dc Menggunakan Arduino ditandai motor on dan off

\begin{tabular}{|c|c|c|}
\hline Motor & On & Off \\
\hline Centrifugal Fan & $\begin{array}{c}40 \text { Detik } \\
\text { (On) }\end{array}$ & Off \\
\hline Motor Hammer & Off & 20 Detik (on) \\
\hline ESP Ready & Off & Off \\
\hline
\end{tabular}

Sesuai dengan waktu kerja yang telah ditentukan, dari waktu kerja tersebut dapat dijelaskan bahwasanya disetting waktu 40 detik EBM Motor Centrifugal dalam keadaan on kemudian 20 detik berikutnya giliran motor hammer yang on dan 5 detik berikut EBM Motor Centrifugal maupun motor hammer dalam keadaan off

2. Kinerja Fan pada prototipe ESP Berdasarkan dari hasil pengujian, berikut Hasil Percobaan pada prototipe ESP :

Tabel 2. Hasil Percobaan

\begin{tabular}{|c|c|l|l|l|l|}
\hline No & Pengujian & \multicolumn{4}{|c|}{ Massa (Mili Gram) } \\
\cline { 3 - 6 } & & Input & $\begin{array}{c}\text { Debu } \\
\text { Rontok }\end{array}$ & Input & $\begin{array}{c}\text { Debu } \\
\text { Rontok }\end{array}$ \\
\hline 1 & Pertama & 2000 & 1146,8 & 3000 & 2081,6 \\
\hline 2 & Kedua & 2000 & 1149,7 & 3000 & 2152,2 \\
\hline 3 & ketiga & 2000 & 1150,2 & 3000 & 2156,8 \\
\hline 4 & keempat & 2000 & 1153,4 & 3000 & 2159,7 \\
\hline 5 & kelima & 2000 & 1155 & 3000 & 2160,1 \\
\hline
\end{tabular}

Berdasarkan hasil dari pengujian yang telah kami lakukan dimana debu yang kami masukan dalam prototipe adalah seberat 2 gram dan 3 gram dengan pengujian masing-masing sebanyak 5 kali. Dimana debu yang berhasil dirontokan oleh motor hammer kemudian di tampung oleh bak penampung hasilnya dapat dilihat pada Tabel 2 . Berdasarkanhasil dari pengujian yang terdapat pada tabel 2 dapat penulis simpulkan bawah rata-rata debu yang berhasil di rontokan dan ditampung di bak penampungan pada pengujian 2 gram debu yang dimasukan pada prototipe adalah seberat 1151,5 mili gram sedangkan pada pengujian 3 gram debu yang dimasukan pada prototipe adalah seberat 2142,8 mili gram.

Hasil dari pengujiantersebut dapat dilihat pada diagram batang berikut :

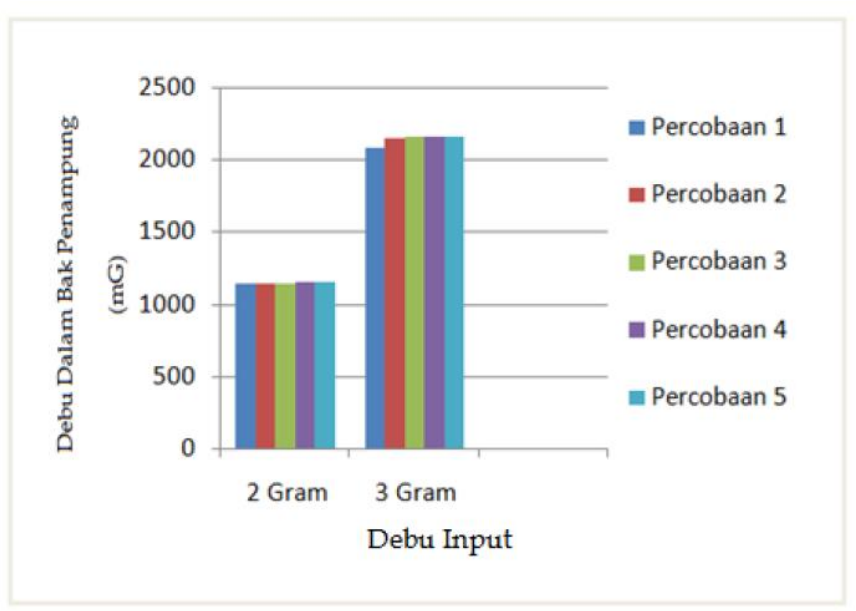

Gambar 7. Hasil Pengujian

\section{KESIMPULAN}

Berdasarkan dari pembuatan danpengujian prototipe ESP, dapat disimpulka sebagai berikut

1. Setelah dilakukan sebuah simulasi setalah saklar di on kan maka arduino akan bekerja memerintahkan relaydan menjalankan motor EC Centrifugal fan selama 40 detik dengan diawali tulisan motor blower on pada LCD kemudian baru motor hammer bekerja selama 20 detik diawali tulisan motor hammer on pada LCD dimana lama waktu kerja dari motor hammer dan EC Centrifugal fan sudah penulis program dalam arduino.

2. Selain mengetahui hasil dari simulasi apakah motor hammerbekerja atau tidak yang ditandai lampu led merah dan biru, penulis juga mengatur kecapatan putar motor/rpm pada motor hammer dan EC Centrifugal fan. Untuk mengatur kecepatan putar motor/rpm penulis menggunaka potensio meteryang terdapat pada modul DC Step Up untuk mengatur kecepatan putar motor EC Centrifugal fan.

\section{REFERENSI}

[1]. EPA. 1985. Operation And Maintenance Manual For Electrostatic Precipitators. Air And Energi Engineering Research Laboratory. Environmental Protection Agency. United States

[2]. Ihsan. 2015. Pengertian Arduino uno, (Online), (http:/ /www.caratekno.com diakses 05 Januari 2017).

[3]. Manual book, Electrostatic Precipitator PT.Semen Gresik, Tuban II Kiln/Rawmill, By FLS miljo. 
[4]. Putra, Ananda, D. 2016. PerancanganPrototipe Electrostatic Precipitator Untuk Penyerapan Debu Discharge. TugasAkhir Program Studi D3 Teknik

[5]. Kelistrikan Kapal, Jurusan Teknik Kelistrikan Kapal, Politeknik Perkapalan Negeri Surabaya. Surabaya.

[6]. Riski, P. 2016. Pencemaran Udara Pabrik Semen Diduga Sebabkan Kematian Warga. Mongabay. Surabaya

[7]. Simanjuntakg.m dan batubara. R.F. 2013. PerencanaanPrototipe Smart GuildiBerbasis Arduino Uno. SengudaEnsikom Volume 2 No 2. Fakultas Teknik Universitas Sumatra Utara. Medan.

[8]. Sohlichin,Zeinus.2018.Pembuatan Prototype Monitoring Dan Kontrol Motor Ac 1 Fasa Berbasis Iot (Internet Of Things) Menggunakan Wemos D1 Mini.TugasAkhir Program Studi D3 Teknik Llistrik, Jurusan Teknik Elektro, Universitas Negeri Surabaya. Surabaya.

[9]. Syaifulhaq, Muhammad. 2014. Perancangan Inverter Half Bridge Zero Voltage Switching Pada Aplikasi Ballast Elektronik Untuk Lampu High Pressure Sodium. Universitas Diponegoro. 